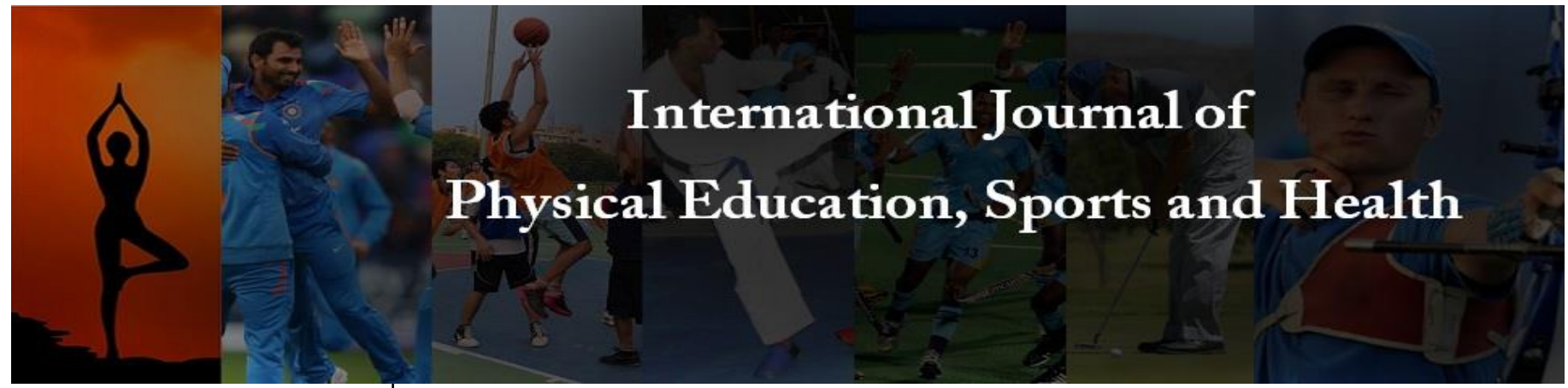

P-ISSN: 2394-1685

E-ISSN: 2394-1693

Impact Factor (ISRA): 5.38

IJPESH 2022; 9(1): 168-173

(C) 2022 IJPESH

www.kheljournal.com

Received: 05-11-2021

Accepted: 29-12-2021

\section{Dr. S Lourdu Raj}

Director of Physical Education, Sree Sevugan Annamalai College, Tamil Nadu, India

\section{Dr. D Maniazhagu}

Associate Professor, Department of Physical Education and Health Sciences, Alagappa University, Tamil Nadu, India
Corresponding Author: Dr. S Lourdu Raj

Director of Physical Education, Sree Sevugan Annamalai College, Tamil Nadu, India

\section{Effects of concurrent strength and endurance training on power}

\author{
Dr. S Lourdu Raj and Dr. D Maniazhagu
}

DOI: https://doi.org/10.22271/kheljournal.2022.v9.i1c.2363

\section{Abstract}

The purpose of the present study was to know the effects of concurrent strength and endurance training on power of junior athletes. Thirty school junior athletes from Alagappa Model Higher Secondary School, Karaikudi were randomly selected as subjects. The age of the subjects ranged between 15 to 17 years. The thirty subject were divided into three equal groups. The experimental group- $1\left(n=10, \mathrm{ST}_{\mathrm{b}} \mathrm{ET}\right)$ underwent strength training before endurance training, the experimental group-2 $\left(n=10, \mathrm{ST}_{\mathrm{a}} \mathrm{ET}\right)$ underwent strength training after endurance training and group 3 served as control group $(n=10, C G)$.The power was chosen as criterion variables and tested by stnding broad jump. The selected two treatment group's were performed three days in a week for the period of nine weeks, as per the stipulated training program. The power was tested before and after the training period. The collected pre and post data was critically analyzed with apt statistical tool of oneway analysis of co-variance. The ability of power have show better in both treatment groups than the control group.

Keywords: Concurrent training, strength, endurance, power, ancova

\section{Introduction}

Athletes to achieve adaptations specific to both forms of exercise commonly perform concurrent training programs involving strength and endurance exercises. Research investigating the effects of concurrent training has typically compared changes in strength and endurance variables after strength training, endurance training or concurrent strength and endurance training. Concurrent strength and endurance training is undertaken by numerous athletes in various sports in an effort to achieve adaptations specific to both forms of training. Literature findings to date, investigating the neuromuscular adaptations and performance improvements associated with concurrent strength and endurance training (referred to as concurrent training) have produced inconsistent results. Some studies have shown that concurrent training inhibits the development of strength and power, but does not affect the development of aerobic fitness when compared to either mode of training alone. Other studies have shown that concurrent training has no inhibitory effect on the development of strength and endurance. Strength and endurance training regimes represent and induce distinctly different adaptive responses when performed individually. Typically, strength-training programs involve large muscle group activation of high-resistance low-repetition exercises to increase the force output ability of skeletal muscle (Sale et al. 1990) [30]. In contrast, endurance-training programs utilize low-resistance, high-repetition exercises such as running or cycling to increase maximum $\mathrm{O}_{2}$ uptake $\left(\mathrm{VO}_{2} \max \right)$. Accordingly, the adaptive responses in skeletal muscle to strength and endurance training are different and sometimes opposite (Tanaka and Swensen 1998) ${ }^{[35]}$. Strength training has been reported to cause muscle fibre hypertrophy, associated with an increase in contractile protein, which contributes to an increase in maximal contractile force (Sale et al. 1990) ${ }^{[30]}$.

Strength training also reduces mitochondrial density and suppresses oxidative enzymes activity which can cause impede endurance capacity, but has minimal impact on capillary density or in the conversion of muscle fibre types from fast twitch (type II fibres) to slow twitch (type I fibres) (Nelson et al. 1990, Sale et al. 1990) ${ }^{[24,30] .}$ 
In contrast, endurance training usually causes little or no muscle fibre hypertrophy, but it does induce increases in mitochondria content, citric acid enzymes, oxidative capacity and the possibility of muscle fibre conversion from fast twitch to slow twitch (Bell 1991, Nelson et al. 1990) ${ }^{[3,24]}$.

\section{Materials and Methods}

The study was formulated as pre and post test random group design, in which thirty junior athletes were randomly assigned into three equal groups. During training, the experimental groups underwent their respective training as per the schedule. Control group maintained normal activities. The following tables show the detailed training program for the period of nine weeks. The total duration of each was 90 minutes. As far as the training variable is concern the frequency was fixed 3 days.

Experimental Group - I

(Strength training before endurance training)

$$
1 \text { - } 3 \text { weeks }
$$

\begin{tabular}{|c|c|c|}
\hline Intensity & $:$ & Low \\
\hline Frequency & $:$ & 3 days / wk \\
\hline Duration & $:$ & 3 week \\
\hline Stations /Circuit & $:$ & 6 exercise stations - clockwise order \\
\hline Duration of Exercise in each Station & $:$ & 15 seconds \\
\hline Set & $:$ & One \\
\hline Rest & $:$ & 30 sec (in between Stations) \\
\hline
\end{tabular}

Endurance Training

\begin{tabular}{|c|c|c|c|}
\hline Weeks & Exercises & Intensity & Repetitions \\
\hline $1-3$ weeks & Extensive Method Run - 1 KM & Low & Single \\
\hline
\end{tabular}

\section{4 - 6 weeks}

\begin{tabular}{|c|c|c|}
\hline Intensity & $:$ & Moderate \\
\hline Frequency & $:$ & 3 days / wk \\
\hline Duration & $:$ & 3 week \\
\hline Stations /Circuit & $:$ & 6 exercise stations - clockwise order \\
\hline Duration of Exercise in each Station & $:$ & 45 seconds \\
\hline Set & $:$ & One \\
\hline Rest & $:$ & 30 seconds (in between Stations) \\
\hline
\end{tabular}

\section{Endurance Training}

\begin{tabular}{|c|c|c|c|}
\hline Weeks & Exercises & Intensity & Repetitions \\
\hline 4-6 weeks & Extensive Method $-1.5 \mathrm{KM}$ & Moderate & Single \\
\hline
\end{tabular}

\section{7 - 9 weeks}

\begin{tabular}{|c|c|c|}
\hline Intensity & $:$ & Moderate \\
\hline Frequency & $:$ & 3 days / wk \\
\hline Duration & $:$ & 3 week \\
\hline Stations /Circuit & $:$ & 6 exercise stations - clockwise order \\
\hline Duration of Exercise in each Station & $:$ & 60 seconds \\
\hline Set & $:$ & One \\
\hline Rest & $:$ & 30 seconds (in between Stations) \\
\hline
\end{tabular}

\section{Endurance Training}

\begin{tabular}{|c|c|c|c|}
\hline Weeks & Exercises & Intensity & Repetitions \\
\hline 7-9 weeks & Intensive Method - 2 KM & Moderate & Single \\
\hline
\end{tabular}

Circuit Activities: Push-ups, High-knee action, skipping, immediately shifted to strength training.

Vertical jump, Squat jump, Jumping Jog.

Note: After Endurance training the Experimental Group II Experimental Group - II

(Strength training after endurance training)

1 - 3 weeks-endurance Training

\begin{tabular}{|c|c|c|c|}
\hline Weeks & Exercises & Intensity & Repetitions \\
\hline $1-3$ weeks & Extensive Method Run - 1 KM & Low & Single \\
\hline
\end{tabular}

Strength Training (Circuit Training)

\begin{tabular}{|c|c|c|}
\hline Intensity & $:$ & Low \\
\hline Frequency & $:$ & 3 days / wk \\
\hline Duration & $:$ & 3 week \\
\hline
\end{tabular}




\begin{tabular}{|c|c|c|}
\hline Stations /Circuit & $:$ & 6 exercise stations - clockwise order \\
\hline Duration of Exercise in each Station & $:$ & 15 seconds \\
\hline Set & $:$ & One \\
\hline Rest & $:$ & 30 seconds (in between Stations) \\
\hline
\end{tabular}

\section{4 - 6 weeks endurance Training}

\begin{tabular}{|c|c|c|c|}
\hline Weeks & Exercises & Intensity & Repetitions \\
\hline 4-6 weeks & Extensive Method - 1.5 KM & Moderate & Single \\
\hline
\end{tabular}

\begin{tabular}{|c|c|c|}
\hline Intensity & $:$ & Moderate \\
\hline Frequency & $:$ & 3 days / wk \\
\hline Duration & $:$ & 3 week \\
\hline Stations /Circuit & $:$ & 6 exercise stations - clockwise order \\
\hline Duration of Exercise in each Station & $:$ & 30 seconds \\
\hline Set & $:$ & One \\
\hline Rest & $:$ & 30 seconds (in between Stations) \\
\hline
\end{tabular}

\section{7 - 9 weeks-endurance Training}

\begin{tabular}{|c|c|c|c|}
\hline Weeks & Exercises & Intensity & Repetitions \\
\hline 7-9 weeks & Intensive Method - 2 KM & Moderate & Single \\
\hline Intensity & $:$ & Moderate \\
\hline Frequency & $:$ & 3 days / wk \\
\hline Duration & $:$ & 6 exeek \\
\hline Stations /Circuit & $:$ & 45 seconds \\
\hline Duration of Exercise in each Station & $:$ & One \\
\hline Set & $:$ & 30 seconds (in between Stations) \\
\hline Rest & &
\end{tabular}

Circuit Activities: Push-ups, High-knee action, skipping, Vertical jump, Squat jump, Jumping Jog.

Note: After Endurance training the Experimental Group II immediately shifted to strength training.

\section{Results}

The results of analysis of covariance on explosive power of different groups (Scores in Metres)

\begin{tabular}{|c|c|c|c|c|c|c|c|c|c|}
\hline \multicolumn{2}{|c|}{ Test Conditions } & $\begin{array}{c}\text { G-1 } \\
\text { ST }_{\mathrm{b}} \mathrm{ET}\end{array}$ & $\begin{array}{c}\text { G-2 } \\
\text { ST,ET }\end{array}$ & G-3 & SV & SS & Df & MS & 'F' Ratio \\
\hline \multirow{2}{*}{ Pre test } & Mean & 1.29 & 1.27 & 1.24 & B & 0.01 & 2 & 0.005 & \multirow{2}{*}{1.2} \\
\hline & S.D. & 0.07 & 0.05 & 0.07 & $\mathrm{~W}$ & 0.12 & 27 & 0.005 & \\
\hline \multirow{2}{*}{ Post test } & Mean & 1.39 & 1.40 & 1.22 & $\mathrm{~B}$ & 0.19 & 2 & 0.09 & \multirow{2}{*}{$24.21^{*}$} \\
\hline & S.D. & 0.06 & 0.04 & 0.07 & $\mathrm{~W}$ & 0.12 & 27 & 0.004 & \\
\hline \multirow{2}{*}{ Adjusted post test } & \multirow{2}{*}{ Mean } & \multirow{2}{*}{1.38} & \multirow{2}{*}{1.39} & \multirow{2}{*}{1.25} & $\mathrm{~B}$ & 0.12 & 2 & 0.06 & \multirow{2}{*}{$56.34 *$} \\
\hline & & & & & $\mathrm{W}$ & 0.03 & 26 & 0.001 & \\
\hline
\end{tabular}

* Significant at .05 level of confidence. The required table's value for test the significance was 3.35 and 3.37, with the df of 2 and 27,2 and 26 .

The pre test mean and standard deviation explosive power scores G1, G2, and G3 were 1.29+0.07, 1.27+0.05 and $1.24+0.07$ respectively. The obtained pre test $\mathrm{F}$ value of 1.2 was lesser than the required table $F$ value 3.35 . Hence the pre test means value of strength training before endurance training, strength training after endurance training and control group on explosive power before start of the respective treatments were found to be insignificant at 0.05 level of confidence for the degrees of freedom 2 and 27. Thus this analysis confirmed that the random assignment of subjects into three groups were successful. The post test mean and standard deviation on explosive power of G1, G2 and G3 were $1.39+0.06$., $1.40+0.04$ and $1.22+0.07$ respectively. The obtained post test $\mathrm{F}$ value of 24.21was higher than the required table $F$ value of 3.37 . Hence the post test means value of strength training before endurance training, strength training after endurance training on explosive power were found to be significant at 0.05 level of confidence for the degrees of freedom 2 and 27 . The results proved that the selected two training interventions namely was strength training before endurance training, strength training after endurance training produced significant improve rather than the control group of the sample populations. The adjusted post test means on explosive power scores of G1, G2 and G3 were $1.38,1.39$ and 1.25 respectively. The obtained adjusted post test $\mathrm{F}$ value of 56.34 was higher than the required table $\mathrm{F}$ value of 3.35 . Hence the adjusted post test means value of, strength training before endurance training; strength training after endurance training on explosive power was found to be significant at 0.05 level of confidence for the degrees of freedom 2 and 26. The results confirm that the selected two training interventions namely strength training before endurance training, strength training after endurance training on explosive power were produced significant difference among the groups.In order to find out the superiority effects among the treatment and control groups the Seheffe's post hoc test were administered. The outcomes of the same are presented in the table I (a). 
Table 1 Scheffe's post hoc test mean differences on EXPLOSIVE POWER among THREE groups

(Scores in Centimetres)

\begin{tabular}{|c|c|c|c|c|}
\hline $\begin{array}{c}\text { G- 1 } \\
\mathbf{S T}_{\mathbf{b}} \text { ET }\end{array}$ & $\begin{array}{c}\text { G- 2 } \\
\mathbf{S T}_{\mathbf{a}} \text { ET }\end{array}$ & $\begin{array}{c}\text { G- 3 } \\
\mathbf{C ~ G}\end{array}$ & Mean Differences & Confidence Interval Value \\
\hline 1.38 & 1.39 & & 0.015 & 0.044 \\
\hline 1.38 & & 1.25 & $0.128^{*}$ & 0.044 \\
\hline & 1.39 & 1.25 & $0.143^{*}$ & 0.044 \\
\hline
\end{tabular}

* Significant at .05 level of confidence.

\section{Pairwise comparision test}

Table 1 shows the paired mean differences of strength training before endurance training, strength training after endurance training and control group on explosive power. The paired wise comparisons results as follows. First comparison: Group 1 and 2: The pair wise mean difference of group 1 and group 2 values 0.015 was lesser than the confidential value of 0.044 . Hence the first comparison was insignificant. The results of this comparison clearly proved that strength training before endurance training and strength training after endurance training were produced better results in explosive power than the control group. However both training have produced similar effects on explosive power. Second comparison: Group 1 and 3: The pair wise mean difference of group 1 and group 3 values 0.128 was higher than the confidential value of 0.044 .

Hence the second comparison was significant. The results of this comparison clearly proved that strength training before endurance training has produced greater improvements on explosive power than the control group. Third comparison: Group 2 and 3: The pair wise mean difference of group 2 and group 3 values 0.143 was higher than the confidential value of 0.044. Hence the third comparison was significant. The results of this comparison clearly proved that strength training after endurance training has produced greater improvements on explosive power than the control group. The adjusted post test mean deference of experimental and control group value graphically represented in the figure.

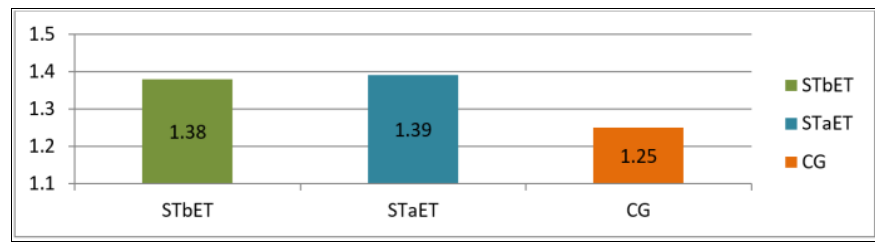

Scores in Metres

Fig 1: Show the adjusted post test mean values of experimental and control groups on explosive power

\section{Discussion on Findings}

Concurrent training studies investigating endurance and strength performance to date have shown mixed results. Nelson et al. (1990) ${ }^{[24]}$ reported that improvements in maximal oxygen uptake $\left(\mathrm{VO}_{2}\right.$ max) during the second half of a 20-week programme were compromised when strength training was implemented into an endurance program. In contrast, a number of studies have found no interference to strength or endurance development because of concurrent training (Sale et al. 1990, Bell et al. 1991, McCarthy et al. 1995) ${ }^{[30,3,21]}$. Sale et al. (1990) ${ }^{[30]}$ suggested that resistance training performed on the same day as endurance training may impede strength development when compared to training for either on separate days. Overall, the most consistent finding from concurrent training literature to emerge was that concurrent training can inhibit strength and power when compared to strength training alone (Hickson 1980, Hennessy and Watson 1994, Hunter et al. 1987, Kraemer et al. 1995) ${ }^{[9,}$ $10,14]$. However, no studies have demonstrated or suggested possible mechanisms for the observed reductions in strength development when utilizing a concurrent program. Strength training is defined as a low number of repetitions performed on a load that is of high resistance, producing a maximal or near-maximal contraction. (Dudley et al., 1985; Sale et al. 1990) [7, 30] In contrast, endurance training is defined as repeated sub-maximal contractions with loads of low resistance. (Dudley et al., 1985; Sale et al., 1990) ${ }^{[7,30]}$ When performed independently, these four distinct forms of training induce for the most part, opposite physiological adaptations within the muscle. Therefore, the adaptation to training that the muscle endures is specific to the training stimulus. Initial gain muscle strength during the first few week of training do not show a concomitant in muscle size or muscle cross sectional area (Mortani. T and H.A. De Vries 1977; Sale. D.G. 1987; Sale. D.G.1988) ${ }^{[28,29]}$. Maniazhagu, D. Susai Arokia Malar (2012) [20] found twenty four weeks of concurrent training effects improve the nature of power.

The quality of the muscle - specifically, type of the muscle proteins that make of the myosin filament changes, but not enough protein is accumulated in the cell to create increase in muscle fiber size. Within several weeks, however, myofibril proteins start to be added to muscle fibers, and increases in muscle fiber size are observed at about 8 to 12 weeks of training. The majority of concurrent training studies have demonstrated that strength development is inhibited during concurrent strength and endurance training programs. However, few authors have attempted to identify why this phenomenon exists (Lervitt 1999). Possible mechanisms have been suggested, which include over-training, conflicting physiological adaptations, muscle fiber type transformations, hypertrophy, endocrine changes, and muscular or neural adaptations. After analyzing the statistical end results the researcher found that the selected training groups have significantly improved the quality of explosive power from the base line to post interventions. The pre to post intervention was present as follows. The strength training before endurance training, group from pre $(1.29+0.07)$, to post $(1.39+0.06)$ and strength training after endurance training from pre $(1.27+0.05)$ to post $(1.40+0.04)$ have significantly changed the pre to post results. The present study demonstrates an increase in explosive power performance of $0.001 \%$ and $0.0013 \%$ for strength training before endurance training, strength training after endurance training. The result of this study proves that both training increased the quality of explosive power significantly over the eight weeks training when comparing control group. However, the strength training after endurance training would produce better improvement than the other training group namely strength training before endurance training. Further strength training after endurance training has produces better improvement on explosive power than the control group. The control group did not show any significant changes on explosive power. In the present study findings in line with above said many study 
findings. Atul Meethal* and Dr. A.M. Najeeb (2013) ${ }^{[1]}$ their study proved that the mud circuit training group had improved the speed, agility, leg explosive power, pulse rate, blood pressure, and aerobic capacity to a greater degree than concrete circuit training group. Taşkin, Halil (2009) conducted a study on effect of circuit training on the sprintagility and anaerobic endurance. Their study shows that the circuit training, which is designed to be performed 3 days a week during 10 weeks of training, improves sprint-agility and anaerobic endurance. The major findings of earlier studies were given briefly here for comparison with the present findings.

Moran, Blagrove, Drury, Fernandes, Paxton, Chaabene, Rami rez-Campillo (2019) ${ }^{[22]}$ investigated a study on effects of small-sided games vs. conventional endurance training on endurance performance in male youth soccer players: a metaAnalytical Comparison. Small-sided games are as effective as conventional endurance training for increasing aerobic endurance performance in male youth soccer players. Buchheit M, et al. (2008) ${ }^{[16]}$ investigated a study on cardio respiratory responses during running and sport-specific exercises in handball players. They found that cardio respiratory responses during small handball games are inversely related to fitness level, coaches are invited to add specific rules to increase the activity of the fittest players. (Hemambara Reddy, D Maniazhagu, 2015) ${ }^{[8]}$ D. Maniazhagu (2019) ${ }^{[18]}$ found that the low and moderate intensities of aquatic plyometric training combined with yogic practices have improved the anaerobic capacity of junior athletes. James Zachariah, D Maniazhagu (2014) ${ }^{[34]}$ conducted a study on comparative effects of different sprint training on anaerobic power. They found that the acceleration sprinting influenced to a great extent on anaerobic power performance. Sridhar, Maniazhagu and Revathi, (2011) ${ }^{[32]}$ found that agility is the key components of the performance of sprint, middle and long distance performance. Study findings from effects of asana practices and stretching exercises combined with neuromuscular drills on cardio respiratory endurance of school girls revealed that the capacity of cardio respiratory endurance was better in asana practices combined with neuromuscular drills. (Maniazhagu, Soniya James, Malar, 2018) ${ }^{[19]}$ Susana et al. (2018) ${ }^{[33]}$ examined a study on ShortTerm Recreational Team Handball-Based Programme on Physical Fitness and Cardiovascular and Metabolic Health of 33-55-Year-Old Men. They found that Recreational team handball practice shows positive physical fitness and healthrelated adaptations, with high attendance, which may contribute to the reduction of the risk of developing lifestyle diseases. In another research findings individual and combined interventions of Tai Chi pilates and yogic practices on cardio respiratory endurance of B.Ed trainees showed that the above training produced significant improvement on cardio respiratory endurance. (S Leo Stanly, Maniazhagu Dharuman, 2020) ${ }^{[25]}$. In another study findings shows that handball coaching program had significant improvement than control group in selected Physical Fitness and Skills performance variables (T. Madhan Kumar and Mebaratu, 2016) ${ }^{[34]}$ A study findings showed that the circuit resistance training have imporved motor fitness variables in men foot ball players. (V Senthil Kumar and D Maniazhagu, 2014) ${ }^{[37]}$ Study results of effects of integrative neuromuscular training on fitness performance in children indicate that integrative neuromuscular training is an effective and time-efficient addition to PE as evidenced by improvements in health- and skill-related fitness measures in children. Schmidt
W, Anderson K, Graff M, Strutz V. (2015) ${ }^{[31]}$, they found that the high intensity circuit training may improve muscle endurance in moderately fit populations. Slight improvements that are gender specific may also be observed in muscle strength as well as aerobic fitness. Atul Meethal* and Dr. A.M. Najeeb (2013) ${ }^{[1]}$ their study proved that the mud circuit training group had improved the speed, agility, leg explosive power, pulse rate, blood pressure, and aerobic capacity to a greater degree than concrete circuit training group. Taşkin, Halil (2009) conducted a study on effect of circuit training on the sprint-agility and anaerobic endurance. Their study shows that the circuit training, which is designed to be performed 3 days a week during 10 weeks of training, improves sprintagility and anaerobic endurance. Physical activities are systematic, planed rhythmic bodily movements aimed to improve physical fitness. (S. Malar, D. Maniazhagu, 2019) ${ }^{[18]}$ Plyometric exercises consist of speedy prevailing movements that involve counter movements or pre stretch. It also called stretch shortening cycle.

\section{Conclusion}

The strength training before endurance training, strength training after endurance training group have produced significant improvement on power, than control group of junior sprinters' responses to the effects of nine weeks training interventions.

\section{References}

1. Atul Meethal, Dr. Najeeb AM. Effects of circuit training on different surfaces on selected physical and physiological variables of school boys, International Journal of Physical Education, Fitness and Sports. 2013 Dec, 2(4). ISSN 2277-5447.

2. Avery Faigenbaum D, Anne Farrell, Marc Fabiano, Tracy Radler, Fernando Naclerio, Nicholas Ratamess A, et al. Effects of integrative neuromuscular training on fitness performance in children, Pediatric Exercise Science. 2011;23:573-584.

3. Bell GJ, Petersen SR, Wessel J, Bagnall K, Quinney HA. Physiological adaptations to concurrent endurance training and low velocity resistance training. Int J Sports Med. 1991;12(4):384-90.

4. Caspersen CJ, Powell KE, Christenson GM. Physical activity, exercise, and physical fitness: definitions and distinctions for health-related research Public Health Rep. 1985;100:126-131.

5. Maniazhgu D. Effects of low and moderate intensities of aquatic plyometric training combined with yogic practices on anaerobic capacity of junior athletes", International Journal of Fitness, Health, Physical Education \& Iron Games. 2019, 6(3).

6. Dr. Maniazhagu D. Effects of two modes of resistance training on speed leg explosive power and anaerobic power of college men students, Indian Journal for research in Physical Education and sports sciences. 2010 Oct-2011 March, 31-34.

7. Dudley GA, Djamil R. Incompatibility of Endurance and Strength Training Modes of Exercise. J Appl. Physiol. 1985;59:1446-1451.

8. Hemambara Reddy, Maniazhagu D. Effects of low intensity of aquatic and land plyometric training on speed, International Journal of Physical Education Sports Management and Yogic Sciences. 2015;(5(1):16-19. http://mirror.uncyc.org/wiki/Throwball

9. Hickson RC. Interference of strength development by 
simultaneously training for strength and endurance. Eur J Appl Physiol Occup Physiol. 1980;45(2-3):255-63.

10. Hunter G, Demment R, Miller D. Development of Strength and Maximum Oxygen Uptake during Simultaneous Training for Strength. 1987, 14.

11. Jagadish Kumar, Maniazhagu D. Effects of interval training on treading and spinning on cardio respiratory endurance of untrained college men International journal of physical education sports management and yogic sciences. 2015;5(3):34-37.

12. James Zachariah, Maniazhagu D. Comparative effects of different sprint training on anaerobic power, Research Reaction \& Resolution. 2014;2(3):20-23.

13. Sudha K, Maniazhagu. Effects of circuit training combined with different neuromuscular activities on muscular endurance and body composition of school girls. Indian Journal of Public Health Research \& Development. 2019;10(12):1329-1333.

14. Kraemer W, Patton J, Gordon S, Harman EA, Deschenes MR, Reynolds K, et al. Compatibility of High- Intensity Strength and Endurance Training on Hormonal and Skeletal Muscle Adaptations. J Appl. Physiol. 1995;78(3):976-989.

15. Leveritt M, Abernethy PJ, Barry B, Logan PA. Concurrent strength and endurance training: the influence of dependent variable selection. J Strength Cond Res. 2003;17(3):503-8.

16. Buchheit M, Lepretre PM, Behaegel AL, Millet GP, Ahmaidi S. Cardio respiratory responses during running and sport-specific exercises in handball players, J Sci Med Sport. 2008. DOI: 10.1016/j.jsams.2007.11.00

17. Malar Maniazhagu. Effects of integrative neuromuscular training combined with yoga and stretching exercises on abdominal strength endurance of primary school children, Indian Journal of Public health research and development. 2020;11(03):899-903.

18. Maniazhagu Malar, Manogari. Effects of circuit training and battle rope training on speed of school girls, Asian Journal of Applied Science and Technology. 2019;3(3):66-72.

19. Maniazhagu, Soniya James, Malar S. Effects of asana practices and stretching exercises combined with neuromuscular drills on cardio respiratory endurance of school girls. International Journal of Research Granthaalayah. 2018;6(10):221-226. https://doi.org/10.5281/zenodo.1486217

20. Maniazhagu D, Susai Arokiamalar. Quantification of selected motor ability components, Physiological and Hematological responses to concurrent endurance trainining and circuit resistance training sequence among college men students. Unpublished Ph.D., thesis, Alagappa University, India. 2012.

21. McCarthy JP. Compatibility of adaptive responses with combining strength and endurance training. Medicine and Science in Sports and Exercise. 1995;27:429-436.

22. Moran Blagrove, Drury Fernandes, Paxton Chaabene, Ra mirez-Campillo. Effects of Small-Sided Games vs. Conventional Endurance Training on Endurance Performance in Male Youth Soccer Players: A MetaAnalytical Comparison. 2019.

23. Moritani T. Time course of adaptations during strength and power training. In strength and power in sports, ed. P.V. Komi: Oxford: Blackwell Scientific. 1992, 266-278.

24. Nelson AG, Arnall DA, Loy SF, Silvester LJ, Conlee RK. Consequences of combining strength and endurance training regimens. Phys Ther. 1990;70(5):287-94.

25. Leo Stanly S, Maniazhagu Dharuman. Individual and combined interventions of tai chi pilates and yogic practices on cardio respiratory endurance of B.Ed trainees International Journal of Physical Education Sports Management and Yogic Sciences. 2020;10(4):2531.

26. Malar S, Maniazhagu D. Effects of integrative neuromuscular training combined with yoga and stretching exercises on abdominal strength endurance of primary school children, Indian Journal of Public Health Research and Development. 2019, 11(3).

27. Malar S, Dr. Maniazhagu D. Effects of two combinations of neuromuscular drills and asana practices on speed, International Journal of Physical Education Sports Management and Yogic Sciences. 2019;9(1);21-25.

28. Sale DG. Influence of exercise and training motor unit activation. Excerc. Sports Sci. Rev. 1987;15:95-151.

29. Sale DG. Neural adaptation to resistance training. Med. Sci. Sports Exerc. 1988;20:S135-S145.

30. Sale DG, Jacobs I, MacDougall JD, Garner S Comparison of two regimens of concurrent strength and endurance training. Med Sci Sports Exerc. 1990;22(3):348-56.

31. Schmidt. W, Anderson K, Graff M, Strutz V. The effect of high-intensity circuit training on physical fitness. J Sports Med Phys Fitness. Epub ahead of print PMID. 2015, 25942012.

32. Sridhar Maniazhagu, Revathi. Comparision of hematological responses to maximal exercise among sprint middle and long distance runners, International Journal of Physical Education Sports Management and Yogic Sciences. 2011;1(1);1-6.

33. Susana Povoas CA, Carlo Castagna, Carlos Resende. Eduardo Filipe Coelho, 6 Pedro Silva, Rute Santos, Rita Pereira, and Peter Krustrup, Effects of a Short-Term Recreational Team Handball-Based Programme on Physical Fitness and Cardiovascular and Metabolic Health of 33-55-Year-Old Men: A Pilot Study, BioMed Research International. 2018. https://doi.org/10.1155/2018/4109796

34. Madhankumar T, Mebaratu. Effect of handball coaching program on selected physical fitness and skill performance variables of Hawassa university handball players, International research journal of physical education and sports sciences. 2016;II(II):1-10.

35. Tanaka H, Swensen $T$. Impact of resistance training on endurance performance: A new form of cross-training? Sports Medicine 25:191-200. Endurance. J Sports Med. Phys. Fitness. 1998;27:269-275.

36. Taşkin H. Effect of circuit training on the sprint-agility and anaerobic endurance, $\mathrm{J}$ Strength Cond Res. 2016;(2):407-14. DOI: 10.1519/JSC.0000000000001123.

37. Senthil Kumar V, Maniazhagu D. Effects of circuit resistance training on selected motor fitness variables, International Journal of Physical Education Sports Management and Yogic Sciences. 2014;4(1):37-40. 